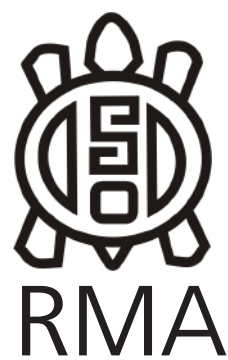

Museología

\title{
Políticas de la representación del folklore en los museos folklóricos
}

\author{
Ana María Dupey* \\ *Sección Folklore, Instituto de Ciencias Antropológicas, Universidad de \\ Buenos Aires. E-mail: ana.dupey@inapl.gov.ar
}

\begin{abstract}
Resumen
Este trabajo trata sobre la invención y la reinvención de los museos de folklore. Se analizan cuáles han sido los propósitos políticos y las razones que se han esgrimido para su establecimiento y quiénes han sido los agentes de estas invenciones / reinvenciones. Si han sido producto de instituciones estatales o surgen de movimientos de elites o grupos minoritarios pertenecientes a la sociedad civil. Simultáneamente, se dilucida cómo las representaciones del folklore son semantizadas para la representación de identidades de colectivos locales, regionales, nacionales y transnacionales. Se analizan a) las actuales re-orientaciones de dichas instituciones operadas a partir de los procesos de descolonización (exteriores e interiores) con sus consecuencias económicas, políticas, sociales y cognitivas, b) las críticas a los análisis coloniales y clasistas desarrollados en el pasado por la Etnología y el Folklore. Disciplinas que abonaron los respectivos discursos museográficos y c) la revisión de la definición de la institución museo.
\end{abstract}

Palabras claves: Museo; Folklore; Política; Museografía; Identidad.

Folklore representation policies in folk museums

\begin{abstract}
This work deals with the creation and re-creation of folk museums. It analyzes the political purposes served and reasons put forward, and the agents responsible for their emergence. It also examines whether they have been the result of state institutions or movements arising from elite or minority groups that belong to the civil society. Simultaneously, it is explained how folklore representations are reconceptualized in the representation of the local, regional, national and transnational collective identities. It analyzes a) the current museum guidelines based on internal and external decolonization processes, and their economic, political, social and cognitive implications; b) the critiques of colonial and classist analyses developed in the past by Ethnology and Folklore -disciplines that influenced museographic discourse; and c) the review of the definition of museum as an institution.
\end{abstract}

Keywords: Museum; Folklore; Politics; Museography; Identity.

Los museos de folklore para el ICOM se encuentran dentro de los de etnografía. Categoría, esta última, que incluye una pluralidad de museos denominados de etnografía, etnología, antropología, museos populares, museos de la cultura popular, Völkerkunde y volkskundemuseum, etc. ${ }^{1}$ Ellos tienen en común que abordan manifestaciones culturales del pasado o de la actualidad que dan cuenta de la diversidad de grupos, pueblos o comunidades. En general, se ha calificado como museo folklórico o de las tradiciones populares o del pueblo o de etnografía regional aquellos en los que se difunden formas 'anacrónicas' de la vida campesina, que enraizadas en su medio local se han desarrollado dentro de las sociedades occidentales. A dichas formas de vida se les han asignado cualidades contrastantes en relación con la modernidad

\footnotetext{
${ }^{1}$ De acuerdo a la definición del Comité Internacional de Museos de Etnografía en: http://icme.icom. museum/index.php?id=3 (Consultada 13-5-2012)
}

como, por ejemplo, conservadoras y tradicionales frente a la innovación y al progreso, con predominio de la oralidad frente a la comunicación escrita, marcadoras de lo provinciano frente a lo cosmopolita, de lo vernáculo frente a lo foráneo y producidas por sociedades en las que priman relaciones interpersonales frente a las mediadas.

Estos museos por más de un siglo y medio, han sido artefactos culturales que han contribuido a la invención de la modernidad y han desempeñado un papel decisivo en la formación de subjetividades modernas/ coloniales -internas y externas- (Walter Mignolo 2009). En tal sentido, han plasmado políticas para representar e interpretar la diversidad de la humanidad estableciendo para ello distinciones entre grupos humanos próximos y lejanos. Distancias argumentadas sobre la base de criterios bipolares: primitivos / civilizados, rústicos / sofisticados, puros / aculturados, foráneos / propios, 
anacrónicos/ modernos etc., no exentos de valoraciones moralizadoras. Asimismo, han experimentado con distintos despliegues museográficos para sostener la fascinación por el descubrimiento del otro. Operación esta última, que le ha permitido al visitante re-conocerse a sí mismo y armar una compleja cartografía de los múltiples otros que lo rodean². Despliegues que si bien han expuesto al visitante a la experiencia con el otro, la representación de ese otro- a través de objetos materialesse ha presentado controlada; ya sea encerrándola dentro de los biselados cristales de las vitrinas donde el visitante podía mirarse a sí mismo en su diferencia o bien en cámaras oscuras que ocultaban la mirada del observador, en una especie de voyerismo antropológico. En dichos despliegues los museos han efectivizado representaciones del otro, a través de dioramas y/o de la organización de continuidades entre los objetos para desarrollar galerías temáticas, que operaban sobre un juego de expropiación /descontextualización de los objetos con respecto a su medio material, social y simbólico de producción y de apropiación/ recontextualización -en términos de las operaciones mediadoras del museo- (Bauman: 2000). Estas operaciones de desprendimiento de los objetos no occidentales de su medio ambiente para insertarlos en otros ámbitos han sido destacadas, por James Clifford, (1988), cuando estudia la exhibición de los objetos "tribales" en el Museo de Arte Moderno.

El museo, a través de las colecciones de su propiedad y la "autoridad" que ha poseído para representar su significado. (Stocking.1985:11), ha tutelado celosamente la relación entre los objetos materiales y los otros que representaban. Sin embargo, a partir de a) los procesos de descolonización (exteriores e interiores) con sus consecuencias económicas, políticas, sociales y cognitivas, b) las críticas a los paradigmas científicos colonialistas y clasistas de la Etnología y el Folklore, disciplinas que abonaron los respectivos discursos museográficos y c) la revisión de la definición de la institución museo (desde aquellas que lo concebían como un "santuario" donde se clasificaban y custodiaban colecciones de obras, que se exhibían para deleite del público hasta las que contemplan la participación comunitaria y privilegian su aporte a la reflexión y al entendimiento de la sociedad), se produce lo que autores como Xavier Roigé I Ventura (2007) denominan: la reinvención de los museos, y otros como W. Mignolo (2009), en clave política, enuncian como la descolonización de los museos; señalando su aplicación para descolonizar la reproducción de la colonización occidental del espacio y del tiempo. Por ello, las perspectivas sobre la reinvención van a ser diferentes, según el espacio donde se localiza la diferencia de la colonialidad. Nico Bogaart (1983:145) desde una nación con historia colonialista como Holanda sostiene que:

\footnotetext{
2 En tal sentido Magnus Fiskesjö (2007) reflexiona sobre como las disputas en torno a un museo sobre pueblos de Asia en Suecia reflejan cómo se piensa la propia sociedad sueca, a partir de cómo se imagina la relación de ellos con "otros".
}

“los museos antropológicos no servirían tanto para transmitir la realidad del Tercer Mundo como para mostrar la manera en que los occidentales la percibimos, cuáles son los elementos y fenómenos que nos impresionan y a cuáles atribuimos importancia. Nos hablarían más de nosotros mismos que de los demás".

En cambio, desde Mali -ex colonia francesa- para Alpha Otlmar Konaré (1983:148)

"Los museos etnográficos no deben poner la mirada únicamente en el pasado y en el mundo rural. Deben tener en cuenta por igual a la ciudad y a la aldea. Prestarán especial atención al estudio de la sociedad precolonial y harán hincapié en la realidad cotidiana del colonialismo, denunciando las teorías racistas"

En el marco de estos procesos, indagaremos la invención y la reinvención de los museos de folklore, cuáles han sido los propósitos políticos y las razones que se han esgrimido para su establecimiento. Interesa destacar quiénes han sido los agentes de estas invenciones / reinvenciones. Si han sido producto de instituciones estatales o surgen de movimientos de elites o grupos minoritarios de la sociedad civil. Simultáneamente, se dilucidarán las representaciones del folklore que se efectivizan y cómo las mismas son semantizadas para la representación de identidades de colectivos locales, regionales, nacionales y transnacionales. Esta propuesta es convergente con las actuales líneas de indagación sobre los diferentes roles de los museos en la producción y modelamiento del conocimiento, que aborda E. Hooper-Greenhill (1999).

\section{Algunos puntos de partida para el análisis.}

Para realizar esta indagación partimos del papel mediador del museo en la construcción y difusión de discursos sociales que materializan imaginarios sociales. Entendiendo a estos últimos, según los desarrollos Magariños de Morentin (cit. Gómez 2001:197). Tomamos en cuenta los aportes de Tony Bennett (1999), quien analiza cómo a partir de la modernidad los museos han sido planteados como instrumentos de educación democrática. Aunque con perspectivas diferentes, que han fluctuado desde las que plantean "llevar la cultura al pueblo" a las que formulan "la democratización de la cultura". La primera de estas perspectivas ha tenido un significativo efecto en el disciplinamiento social, en términos cognitivos en cuanto a los imaginarios que inculcan y en los comportamientos sociales que infunde en relación con los objetos y las personas que se desenvuelven en la esfera pública del museo. Esta capacidad de disciplinamiento, se ha basado en la histórica división entre el conocimiento experto de quienes los organizan y el de los receptores. Esta separación -que incluso se expresa físicamente entre por un lado, los gabinetes de trabajo sobre las colecciones y la organización de las muestras y por otro, las salas habilitadas al público- ha producido un discurso monológico dominado por la autoridad del museo. 
Por ello, estas instituciones han constituido campos específicos para ejercitar el poder de inculcar supervisadas representaciones e interpretaciones sobre determinados temas para hacerlos social y políticamente relevantes en la esfera pública. Las actuales perspectivas se orientan a romper con esta lógica, favoreciendo discursos dialógicos que propicien el debate, permitiendo que los museos funcionen como sitios para la formulación de propuestas plurales, diferentes y comunitariamente participativas.

Para este trabajo se eligieron museos que por sus denominaciones, los textos que producen y los objetos que exhiben son identificados como relacionados con el folklore. En cuanto al significado asignado al término, no lo definimos a priori. Lo recuperamos a partir de las acciones producidas para significarlo. Específicamente, a través de las operaciones para materializarlo desplegadas por la propia institución: autodenominación, producción de textos, formas de nombrar, ordenar, clasificar y contextualizar los objetos que exhibe, y la incorporación de performances ${ }^{3}$ folklóricas. En este proceso de representar y dar significación a lo folklórico se ponen en juego una variedad de repertorios, de cuerpos de saberes, de géneros discursivos, y universos simbólicos presentes en la sociedad, a partir de los cuales se establece el sentido particular de lo folklórico que plasma el museo. En algunos casos, denominaciones tales como, museo etnográfico, de las tradiciones, o del pueblo constituyen equivalentes del término folklórico por hacer referencia a una vida campesina anacrónica, especialmente en países colonialistas, dado que a partir de los procesos de descolonización se desplazaron los estudios etnográficos que realizaban entre los nativos de las colonias hacia los nativos de la metrópoli. Interesantes discusiones sobre este desplazamiento, tanto en los medios académicos como en el ámbito museológico, son desarrolladas por Zumwalt (1982) Segal en (2005) y van Ginkel y Henkes (2003).

Para indagar los discursos en los que se representa e interpreta lo folklórico se han consultado distintas fuentes. Para los discursos históricos se ha revisado documentación, que obra en los archivos de los museos:

\footnotetext{
${ }^{3}$ La noción de actuación ha sido desarrollada por: a) los estudios del ritual y la acción simbólica (Van Gennep, V. Turner, R. Schechner) y b) desde la sociolingüística, etnopoética, etnografía del habla (Bauman Sherzer, Goosen, Dell Hymes, D. Tedlock Ch. Briggs). Los autores de esta última tendencia abordaron la actuación folklórica como un evento comunicativo en el cual la función poética es predominante y la experiencia que se invoca es resultado del uso de recursos poéticos y estéticos, a partir de múltiples recursos comunicativos. La actuación folklórica es caracterizada por 1) la exhibición del comportamiento artístico frente a otros, b) la responsabilidad de la competencia asumida por el intérprete ,c) la evaluación, por parte de los participantes (si fue una actuación lograda o no) ,d) la calidad expresiva de la experiencia para los participantes, e) las claves metacomunicacionales que indican que se trata de una performance y se usan para llamar la atención de los participantes en torno al sentido especial de la comunicación. Claves que indica cómo debe ser interpretado el evento comunicativo generando un conjunto de expectativas en relación con la performance (Langdon, E.J 2007)
}

catálogos, instructivos para el armado de colecciones, guías y cuestionarios para registro de expresiones folklóricas, fotografías de exhibiciones, documentos oficiales sobre políticas culturales. Con respecto a los discursos actuales se han tomado en cuenta los sitios de internet oficiales de los museos, de sus colecciones y actividades en donde se autorepresentan a través de textos, imágenes, videos.

\section{Museos folklóricos y la construcción de lealtades políticas}

Los museos han sido espacios de representación del folklore con distintos propósitos y distintas razones. Tempranamente el rey Oscar II, quien gobernaba Suecia y tenía bajo su dominio a Noruega, organizó en su residencia de verano la exhibición de una colección de artefactos representativos de Noruega de su propiedad (1881). Esta práctica trataba de fortalecer el vínculo entre el monarca y los pueblos bajo su dominio. De este modo, la casa gobernante de origen extranjero buscaba nativizarse y asegurarse la lealtad de los súbditos, adoptando expresiones de la cultura tradicional campesina, connotada por su arraigo al suelo local. Posteriormente, para celebrar y consolidar públicamente este vínculo se relocalizaron viviendas rurales tradicionales procedentes de distintas regiones de Noruega emplazándolas, justamente, en el centro político del reino: la sede de la residencia real en Bygdøy. Estos antecedentes orientaron la creación del actual Norsk Folksemuseum en 1894 en Oslo, como museo al aire libre. Sin embargo, la dinámica social y política -debilitamiento del apoyo a la Unión política entre Noruega y Suecia y emergencia de movimientos nacionalistas-, llevaron a redefinir la orientación del museo. Este se concentraría en coleccionar piezas sobre la cultura campesina de los noruegos diferenciada del mundo escandinavo -categoría más englobante- y su representación se ajustaría a un programa científico que separaba la cultura tradicional rural (folk) de la de los pueblos primitivos, (esta última se representaría en los museos etnográficos) y clasificaba la exhibición de los artefactos culturales por origen geográfico. Posteriormente, se reformuló como museo dedicado a la historia cultural de la vida cotidiana y del mundo del trabajo de Noruega desde el siglo XVI a la actualidad. De este modo, se incluyeron otros sectores sociales, perdió la preeminencia el mundo campesino y se incorporaron los sectores populares urbanos y de clase media. Se buscó conectar la sociedad del pasado con la del presente. Prueba de esta extensión temática, es que hoy no solo incluye los edificios tradicionales -que representan distintas regiones de Noruega- sino que se han incorporado construcciones pertenecientes a sectores urbanos medios, de los años 60 . Si bien se registran estas transformaciones, es destacable que de las nueve exhibiciones permanentes, tres se dedican al mundo rural tradicional: la de los trajes típicos -que comprende desde indumentaria ceremonial hasta las ropas de trabajo-, la de las artesanías tradicionales y la de las armas de la vida 
rural y una tercera, la de los juguetes se prolonga hasta el siglo XX. En relación con las poblaciones originarias, los Sami, recién en 1957, van a estar representadas en sus colecciones y muy, posteriormente, van a ser objeto de una exhibición especial.

Sin embargo, es en el plano de las actividades que el museo propone a los visitantes en donde se intensifica la representación de lo folklórico. En una de las propuestas se los invita a participar en escenas vivientes dentro de los edificios históricos en relación con actividades cotidianas de la vida premoderna folk haciéndoles presente el pasado (presentificación de lo ausente). En otra actividad, se les da la posibilidad de realizar tareas vinculadas al trabajo rural a la vieja usanza en las granjas que posee el museo, asumiendo quienes participan ser "el folk" (campesino tradicional). Finalmente, se los invita a participar en celebraciones de festividades tradicionales y sesiones de danzas folklóricas - con trajes tradicionales-, en las que el museo se erige en trasmisor de la tradición del folklore ante la audiencia.

\section{Movimientos nacionales, regionales y panregionales en la formación de museos folklóricos}

Si bien los museos folklóricos, han tenido un papel significativo en la construcción de imaginarios nacionales y en la incorporación ciudadana de poblaciones excluidas de la participación política, por su función educativa, en el caso de Suecia, tuvieron un papel preponderante en la difusión de un imaginario panregional: el escandinavo. Esta forma de imaginación concebía a Suecia, Noruega y Dinamarca como una región transnacional basada en la proximidad nórdica, en haber conformado durante el medioevo una unidad política -la Unión Kalmar-, y en que compartían una edad de oro vikinga, una mitología y un mundo simbólico común (Götz, 2008, Aronson, 2008). Se enfatizaba la homogeneidad y la unidad panregional. Esta tendencia se plasmó en las operaciones de recolección de artefactos culturales como la que Artur Hazelius, representante de este movimiento, llevó a cabo. Este reunió una colección de objetos tradicionales de distintos países nórdicos vinculándolos a un pasado común para celebrar la unidad cultural del pueblo escandinavo, con miras a establecer una nación pan escandinava (Hillström, 2010). En 1873 se exhibió al público la Colección Etnográfica Escandinava que, posteriormente, dio origen al museo Nordiska (1880). Sus exhibiciones comprendían expresiones culturales campesinas de distintos países nórdicos. Las formas expositivas adoptadas por Hazelius se inspiraron en las desarrolladas en las exposiciones mundiales, tales como la de reconstruir el contexto "natural" de los objetos, desarrollar dioramas interiores de viviendas, y reproducciones parciales de exteriores de viviendas de distintas regiones de Suecia. Se incorporaron maniquíes de cera con trajes típicos, y el despliegue de una profusa cantidad de objetos en vitrinas (Hillström, 2010). En su tiempo el mensaje de la muestra fue cuestionado por quienes deseaban promover la idea de una nación sueca y efectuar el mapeo de su territorio. Solo después de la muerte del fundador y director del museo, se definió el enfoque y se decidió nacionalizarlo para fortalecer los sentimientos nacionales y valores patrióticos del pueblo sueco. No obstante, esta resolución recibió críticas de Gunnar Hazelius, quien afirmaba las raíces comunes y el sentimiento de afinidad de la comunidad escandinava así, como también, la artificialidad de las fronteras políticas para el pueblo nórdico. Sin embargo, la crisis de la Unión entre Suecia y Noruega, que culminó con la independencia de esta última, va a precipitar el inicio de un proceso de alterización de Suecia como nación con respecto al imaginario panregional destacando su diferencia y singularidad. Para ello, se separaron las colecciones no por la cultura de los pueblos sino por países y regiones. En todo este proceso la cultura folk (preindustrial) va a ser la base para nacionalizar al museo.

La otra creación de Artur Hazelius, fue el museo Skansen. Este se caracterizaba por conjuntos de edificios rurales -trasladados expresamente desde diferentes lugares de Suecia-, en cuyos interiores se recompusieron mobiliarios y utensilios y donde personas vestidas con los trajes de las localidades recibían a los visitantes. Estas escenas vivientes que simulaban el entorno original producían un efecto de ennoblecimiento de la comunalidad de la sociedad campesina sueca, destacando su estabilidad social e invisibilizando toda conflictividad política. Esta idea romántica de una cultura rural detenida en el tiempo, presentada en retroceso con respecto a la industrial, favoreció la emergencia de sentimientos de nostalgia hacia dichas sociedades. Ciertas regiones -como es el caso de Dalecarlia- eran presentadas como aquellas que conservaban el auténtico estilo de vida folk sueco.

Los actuales discursos del museo mantienen la relevancia del mundo rural, de la vida en las pequeñas aldeas y de los oficios de los artesanos. Las exhibiciones se complementan con la actuación de grupos de danza con trajes tradicionales, que interpretan bailes folklóricos. Se celebran fiestas tradicionales del ciclo anual (Santa Lucia realizada con motivo del solsticio de invierno, Walpurgis efectuada entre el 29 de abril y el 10. de mayo, etc.) y se dedican días a determinados temas. Solo recientemente se ha incorporado a un grupo históricamente marginado, el pueblo Sami -indígenas del ártico- mediante charlas sobre su identidad y demostraciones sobre sus artesanías y gastronomía 4 .

\section{Museos folklóricos y localismos.}

Otros movimientos del siglo XIX se desarrollaron en el seno de sectores sociales medios cultos (poetas, periodistas, maestros, historiadores locales) para quienes la lengua, la literatura y la cultura local estaban relacionadas con su

\footnotetext{
4 Tal cual se desprende de la programación informada en el sitio / www.skansen.se/Consultada 12 -2- 2011
} 


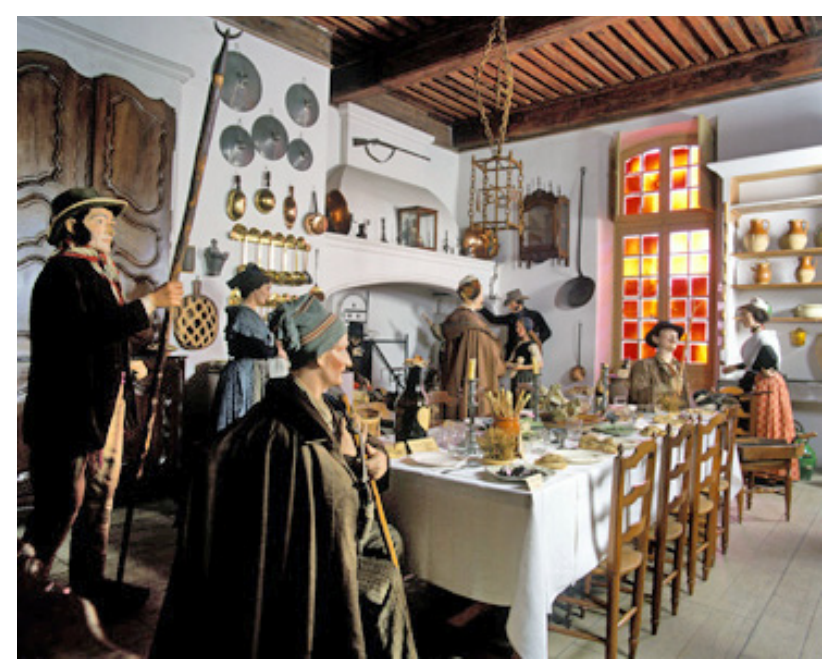

Figura 1. Diorama: Escena de la vigilia de la Calendale, ciclo de fiestas de la Navidad que comienzan el 4 de diciembre

Figure 1. Diorama: Scene of la Calendale eveningleve, the Christmas period starting on December 4th. (Coll. Museon Arlaten, musée départemental d'ethnographie, Arles, cliché J.L)

movilidad social y política. Tal es el caso del Felibrismo ${ }^{5}$ que llevó a uno de sus representantes Frédéric Mistral, ${ }^{6}$ no solo a defender el mantenimiento del provenzal y la langue d'oc (occitana) como reacción a las políticas asimilacionistas del gobierno para imponer el francés- a través del sistema educativo, la prensa y el servicio militaren todo el territorio de Francia, sino que también fundó el Museo Arlaten (1896), para preservar el estilo de vida particular de la región de la Provenza y legitimar la cultura de la misma. El museo fue organizado en salas temáticas y se adoptó como forma expositiva: el diorama. Las mismas abordaban temas de la vida tradicional provenzal tales como el nacimiento de un niño, las fiestas del ciclo de Navidad, la devoción religiosa representada por una mujer con el traje tradicional de Arles rezando en un oratorio y el trabajo de las costureras en un taller. Las tres primeras fueron concebidas por Frédéric Mistral y Emile Marignan entre 1897-9 y hacían referencia a memorias de Mistral en su calidad de nativo de la región. En otra sala, que estaba dedicada a ritos y leyendas de la localidad, se multiplicaban copiosas colecciones de reliquias, exvotos, y talismanes con marbetes explicativos en vitrinas centenarias. Esta proliferación de objetos producía materialmente una evocación mimética del mundo

\footnotetext{
5 "Este renacimiento literario se inicia fomentado por dos corrientes divergentes, la una funcional y psicológica, que pretendía comunicar con el pueblo y rehabilitar su dignidad humana elevando su lengua, y la otra estética, que pretendía reanudar con una brillante literatura trovadoresca. Ambas corrientes coinciden en la estimulación de un sentimiento de pertenencia e identidad territorial distinta a la del norte de Francia, en un siglo en el que el devenir político de la nación francesa está continuamente amenazado por guerras, golpes de estado, insurrecciones y rebeliones". (Mellado García 2008)

${ }^{6}$ El poeta provenzal, funda en Arles (Francia ) Félibrige o felibrismo, que trató de devolver su antiguo esplendor a la lengua y a la literatura Provenza.
}

virtual de las creencias locales para llamar la atención del visitante sobre la particularidad de las mismas.

Asimismo, para fortalecer la tarea del museo y dar mayor difusión pública al folklore provenzal y preservarlo, Mistral creó en 1904 la Festo Vierginenco en la que se establece el uso del traje folklórico entre las aspirantes a reinas del Felibrige, inventando una tradición, que continúa hasta la actualidad.

A partir del 2006 se encaró el proyecto de la renovación del museo ${ }^{7}$. El mismo se focalizó en la obra de Mistral como constructor de la memoria colectiva provenzal. Se buscaba recuperar el proceso de institucionalización del folklore provenzal para que los miembros de la sociedad local objetiven y reflexionen sobre cómo se fue representando la identidad regional. Las salas temáticas se re-organizaron en cinco secuencias cronológicas desde finales del siglo XIX hasta principios del siglo XXI, complementadas por una sala temporal, para favorecer la reflexión sobre el papel del museo en la experiencia de la identidad provenzal, tanto para nativos como para foráneos

\section{De la representación del pueblo de la nación a las diversidades del multiculturalismo}

Naciones multiétnicas van a apelar a los museos como instrumentos en sus políticas de integración nacional. En pleno desarrollo de la 2da República en España (19311939), se promovió la fundación del Museo del Pueblo Español donde se va a organizar una cartografía de identidades culturales regionales para subsumirlas en una entidad política más englobante, la de pueblo español. Sus colecciones se formaron a partir de donaciones y adquisiciones producidas con motivo de la exposición del traje regional realizada en Madrid en 1925. Esta muestra al exhibir los trajes populares tradicionales (folklóricos), de acuerdo a la provincia de origen, los proponía como señales icónicas de las identidades de los residentes de cada región representada. De este modo, se estableció la idea de que el traje era algo que estaba en lugar de "alguien" -su portador- que pertenecía a otro lugar -a una determinada comarca-. Si la estética del traje operó como el medio de acercarse al otro regional, la distribución geográfica actúo como un eje ordenador de la diversidad de trajes/identidades telúricas. Produciéndose una reificación y estererotipación de las identidades folklóricas. Esta cartografía presentó una idealización no conflictiva en la articulación entre el deseo de mantener las identidades regionales y la consolidación de la identidad nacional, porque el emplazamiento físico continuo de los trajes en las exhibiciones producía el efecto de la unidad de las regiones con la nación. Esta colección constituyó la base del museo del Pueblo

\footnotetext{
${ }^{7}$ El proyecto de renovación se obtuvo del sitio: http://www.museonarlaten.fr/museon/webdav/site/museon/shared/ content/dp.pdf consultado 10-2-2010
} 


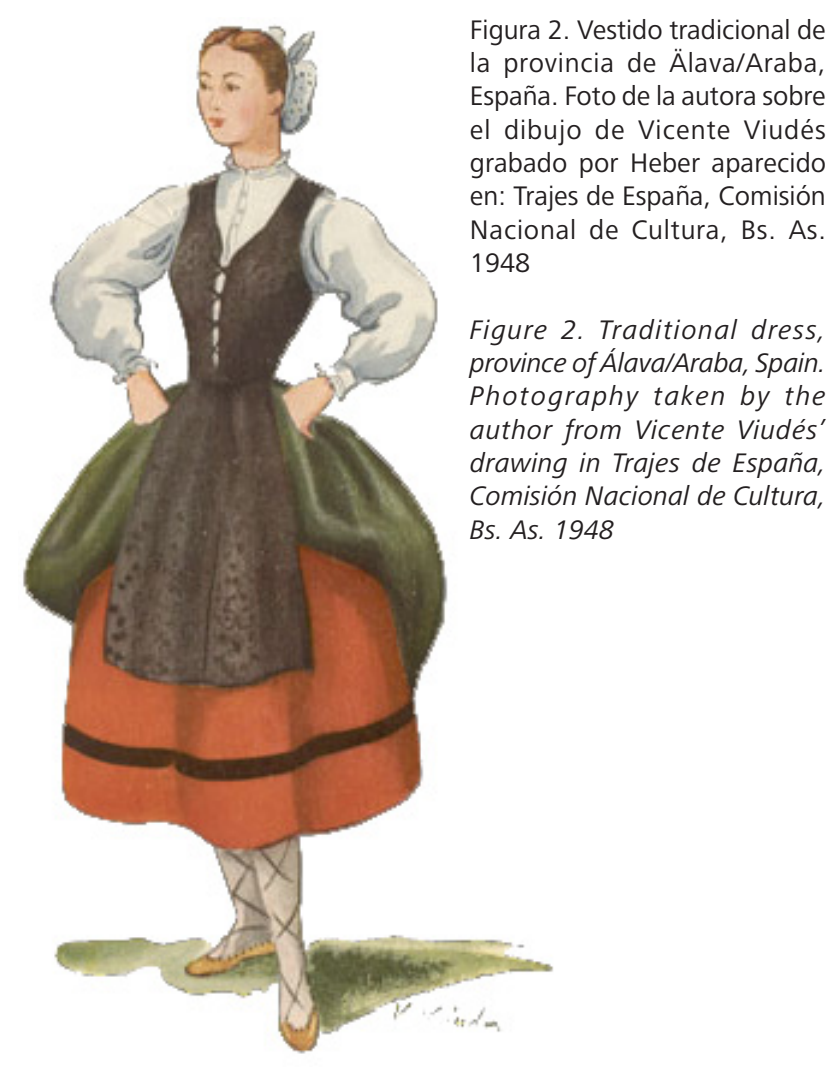

Español, que logró fundarse durante la 2da República en 1934. En su decreto fundacional No. 92, se da cuenta de su propósito de la siguiente manera:

"Cumple el Gobierno con la deuda cultural y política contraída por la República con el "Pueblo Español",/ que no tiene, un Museo adecuado que recoja/ "las obras, actividades y datos del saber, del sentir y el actuar de la masa anónima popular, perdurable y sostenedora, a través del tiempo, de la estirpe y tradición nacionales, en sus variadas manifestaciones regionales y locales, en que la raza y el pueblo, como elemento espiritual y físico, han ido formando nuestra personalidad étnica cultural." (AMPE, I, 1935: 5).

El museo funcionó como tal hasta 1993, aunque solo estuvo abierto al público entre 1971 y 1973. En dicho decreto, se incluyó la previsión de mantener una sección especial del Traje Histórico:

"Conservará y continuará la sección especial del Traje Histórico, ampliándola con el de oficios y jerarquías", art. $2^{\circ}$ ) en atención a la procedencia de una parte de sus colecciones - tarea que el Museo nunca desatendió- "sus fondos continuaron creciendo." (Carretero Pérez 2007: 16)

Por ello, y a pesar que su primer director Luis Hoyo Sainz reclamaba considerar todos los aspectos etnográficos y folklóricos de las regiones, el traje mantuvo la centralidad en el despliegue museográfico. Otra cuestión significativa, que se planteó en relación con el funcionamiento del museo, era la participación de integrantes de la sociedad civil-ya sea por su afición hacia la región de origen y a sus tradiciones o su inclinación por carácter nacional español o casticismo- mediante su incorporación como encuestadores en el terreno, para ello se les suministraba cuestionarios guías. Así lo expresaba la Circular para la Recogida de Objetos:

"No puede constituirse plenamente el Museo del Pueblo Español con la sola protección oficial, científica y económica, pues a nutrirle han de contribuir cuantos sientan un patriotismo tradicional al espíritu de raza y un casticismo ${ }^{8}$ regional y local, que destaque y conserve las unidades históricas y geográficas que integran la Nación"

Finalmente, mediante el Real Decreto 684 fue transformado en Museo Nacional de Antropología en 1993, reconvertido en Museo del Traje-CIPE en 2004 y proyectado como Museo Nacional de Etnografía. Este último para dar cuenta:

"de la memoria histórica y vida cotidiana de España. Con miles de piezas que cubren un período de 500 años de historia común, el museo será un centro referente nacional e internacional"9

En el marco de las políticas culturales del gobierno francés del Frente Popular (1936-1938), que proponían la popularización de la cultura, sobre la base de las colecciones del Museo de Etnografía del Trocadero se crearon el Museo del Hombre y el Museo Nacional de las Tradiciones Populares (MNTP), responsables, uno sobre la tematización etnológica de los hombres primitivos del presente y los fósiles y el otro sobre la cultura popular tradicional. Surgieron con una doble vocación de conservación e investigación. El MNTP organizó encuestas nacionales en terreno a partir de cuestionarios estandarizados sobre artesanías, arquitectura, alimentación, mobiliario, festividades y derecho consuetudinario en distintas regiones para el estudio de la vida tradicional. Posteriormente, el régimen de Vichy (1940-44) transformó estas instituciones. En el caso del MNTP fue puesto al servicio de la glorificación de las virtudes campesinas y las tradiciones ancestrales. Sin embargo, el museo pensado como el "Louvre del pueblo"

\footnotetext{
8 " é uma postura literária, cultural e ideológica, manifestada em Espanha desde o século XVIII em oposição à afrancesada ou ilustrada, e que desde então se relaciona com o pensamento reaccionario. É uma reivindicação defensiva do castizo, ou seja, das expressões de todo o tipo (culturais, religiosas, vitais, moda, atitudes, fala, ou inclusive da organização política e social),[1] que se percebam pelo casticista como próprias de sua casta, entendida esta não tanto como a raça ou etnia própria (se veja Racismo em Espanha), senão mais bem como o carácter nacional espanhol, a boa casta, inclusive em termos reproductivos vagamente machistas, que fizeram parte do nacionalismo espanhol, sobretudo em suas expressões mais populares e nas expressões de orgulho patriótico habituais durante o franquismo.[2] http://pt.encydia. com/es/Casticismo consultada 12-2-2011

9 De acuerdo a lo enunciado en nota aparecida en Público.es digital alojado en el sitio:

Ihttp://www.publico.es/culturas/192436/el-museo-de-la-vida-cotidiana-en-teruel
} 
no fue abierto al público hasta 1972, bajo el impulso del ministro de cultura André Malraux. En su inauguración estrenó una museografía novedosa caracterizada por galerías temáticas sobre la vida material e inmaterial de la cultura francesa tradicional. Los objetos eran presentados en cámaras oscuras suspendidos por hilos invisibles, situando los objetos en sus contextos materiales de producción, destacando los procesos técnicos artesanales ofreciendo una visión sintética de la sociedad francesa tradicional en sus aspectos rurales y artesanales, pero anclada en el pasado.

Posteriormente, renovaciones teóricas provocaron el abandono de la ilusión de la comunidad campesina aislada y la construcción de la variación de las expresiones folklóricas ordenadas por regiones para ilustrar la diversidad de las prácticas culturales en los espacios franceses. Se cuestionaron las descripciones de las áreas culturales que llevaban a definir identidades artificiales y despolitizadas. Todo ello motivó a que en junio del 2005 se cerraran sus puertas y sus colecciones se trasladaran a Marsella para ser reinventado como Museo de las Civilizaciones de la Europa del Mediterráneo (MuCEM), centrado en la cultura popular francesa pasada y actual y del Mediterráneo europeo en clave comparativa e intercultural.

\section{Museos folklóricos y federalismo político}

Los estudios folklóricos tuvieron en Tucumán (Argentina) un ambiente propicio, en la primera mitad del siglo XX. Desde 1927 Juan Alfonso Carrizo recibió apoyo para sus recopilaciones de los cancioneros del NOA por parte de Ernesto Padilla. En 1937 siendo rector de la Universidad Nacional de Tucumán Julio Prebisch, se creó el Instituto de Historia, Lingüística y Folklore, a cargo de Manuel Lizondo Borda. Destacados investigadores del folklore visitaron la universidad, entre ellos el Dr. Raúl Cortazar quien presentó para su edición por el sello universitario su libro "Bosquejo de una introducción al folklore", que produjo una renovación epistemológica en el estudio del folklore. En el Instituto de Historia, Lingüística y Folklore, cumplía funciones en la Sección Folklore, Rafael Jijena Sánchez, quien promovió la creación del Museo Folklórico Provincial General Manuel Belgrano en noviembre de 1943. Este surgió en el marco de la política oficial del gobierno para afirmar la cultura tradicional local y la autonomía federal frente al centralismo político de Buenos Aires. Su fundación fue coetánea con el movimiento de intelectuales y literatos denominado La Carpa, que se gestó en la provincia con la idea de refundar las letras del NOA. Sus integrantes en el Prólogo de la Memoria Colectiva de Poemas, que publicaron en 1944, aportaron nuevas perspectivas en torno a las políticas del folklore, que disentían con las desarrolladas por el museo. Como señala Martínez Zuccardi (2010) cuestionaban la forma en que los regionalistas habían asumido la pertenencia al Noroeste, a través del nativismo. Ellos se consideraban próximos a la tierra y a las tradiciones pasadas de los sectores populares pero a través de un compromiso estético, ético y político. Se distanciaban de los "poetas folkloristas" que utilizaban las expresiones del arte y del saber popular en su lírica. Rechazaban a aquellos que tomaban de la tierra lo anecdótico. Se opusieron a quienes recurrían a los giros regionales pintoresquistas para dar cuenta de la problemática popular e indígena Mientras que los representantes de este grupo realizaban una operación reflexiva acerca de cómo se venía representando el folklore, el museo adoptaba una postura culturalista, la que más abajo se desarrolla.

En 1957 - por Decreto Ley 4/54- se cambió la denominación del museo por la de Museo Folklórico del Noroeste "Manuel Belgrano" e Instituto de Estudios Folklóricos de Tucumán y fue designada como directora María Delia Millán de Palavecino. En la Memoria Anual (1957) que ella presentó a las autoridades justifica por un lado, la ampliación de las competencias de la institución porque se abordaría el área cultural folklórica del Noroeste, caracterizada por una constelación de rasgos que por la simple continuidad espacial la individualizaba frente a otras áreas. La cultura folklórica- según la conceptualización de E. Palavecino (1959)- constituiría:

"un repositorio de técnicas y pensamientos primitivos integrados a un estilo de vida social, y estéticamente tradicionales, que adquieren un relieve singular en oposición a la sociedad industrial" (p.349).

Entre los rasgos constitutivos de dicha cultura folk se hallarían elementos indígenas pero organizados dentro de un sistema político, religioso y social europeo. Por lo que la corriente cultural hispana al mezclarse con las capas culturales indígenas del noroeste en los siglos XVI y XVII, habría configurado la cultura folk del noroeste Este concepto que proyectaba el folklore hacia el pasado y lo escindía de la actualidad y de sus condiciones materiales y sociales de producción va a definir las colecciones del museo y las temáticas expositivas. Por otro lado, en el mismo documento se argumentaba la creación de un Instituto de investigación porque permitiría dar explicaciones sobre los materiales culturales en base a un saber razonado, según un método científico. Complementariamente, se planteó la renovación museográfica de las formas expositivas del museo adoptando carteles, fotografías, dibujos, esquemas técnicos, paneles etc. para dinamizar su función educativa. La organización de la exposición fue desarrollada en cuatro salas: 1) la de manufacturas del Noroeste en las que se presentaban artesanías folklóricas y sus técnicas de fabricación 2) la de indumentaria argentina distinguiéndola por provincia, 3) la de vida rural con la reconstrucción de un ambiente en una casa rural y 4) la de imaginería e instrumentos musicales. Distinguiendo en cada uno de los artefactos, su procedencia indígena o europea. Como se observa M.D. Millán de Palavecino plasmó museográficamente la noción de área de cultura folklórica. Privilegió constelaciones espaciales 
de artefactos culturales materiales y sus procesos de construcción -no se hacía referencia a la organización social de quienes los poseyeron ni a su arte verbal (leyendas, mitos). Este concepto expositivo se mantuvo hasta los 90, cuando se encaró la refacción del edificio, que fue acompañada de significativos cambios. El museo se planteó como un espacio de revalorización de la cultura y las tradiciones en su diversidad de manifestaciones y de salvaguarda de la memoria. Se remozaron las formas expositivas con la reproducción de un rancho norteño con todos sus elementos característicos y medios de transporte de la época. Se crearon salas dedicadas a personajes destacados en la difusión del folklore musical contemporáneo vinculados ya no a un medio folk sino a las industrias culturales modernas, como son la dedicada a Mercedes Sosa y a los Tucu Tucu y en su desarrollo se incorporaron recursos multimedia Se introdujeron performances del arte verbal tradicional (relatos sobre "El Duende, "La Viuda", "El Familiar", "La Mulánima", "La Salamanca" etc.) utilizando recursos sonoros no tradicionales.Por otro lado, se ha venido desarrollando una tarea participativa de la comunidad y de inclusión de la cultura tradicional de grupos antes no contemplados por el museo, como es el caso de las colectividades extranjeras (sirios libaneses, asturianos, italianos, belgas y peruanos). Se debaten películas como Tucumán Arde, que en la década de los 60 cuestionó el enfoque museístico despolitizado de los grupos folklóricos rurales al denunciar las condiciones de explotación de los trabajadores de los ingenios azucareros. Obra que aborda el compromiso ético y político anticipado por los integrantes de La Carpa.

De este modo, el museo ha adquirido un carácter dialógico en el que se encuentran representadas múltiples voces ofreciendo instancias reflexivas en torno a la política de la representación del folklore.

\section{Conclusiones preliminares}

El itinerario de este trabajo pone en evidencia como la lógica seguida para la invención de los museos folklóricos ha estado dominada por categorías vinculadas a concepciones de la disciplina del Folklore del siglo XIX, centradas en una alteridad construida a partir de la cultura rural en retirada frente a los avances de la Modernidad, a fin de dar cuenta de esta última. Al apartar los grupos folk del presente y proyectarlos hacia el pasado se invisibilizaron las relaciones con la sociedad mayor de la que participaban y se opacó la dinámica de los cambios que ocurrían en los mismos. Por ello, en los despliegues museográficos se privilegiaron enfoques centrados en los objetos y/o en escenificaciones mediante dioramas y escenas vivientes que trataban de imitar el contexto social del folklore ${ }^{10}$. Aunque éste era un recurso artificioso que

\footnotetext{
10 Entre el siglo XVIII y XIX los desarrollos museográficos se orientaron a la representación de la realidad valorando la aprehensión sensible directa de los objetos. Desde esta perspectiva los objetos adquieren especial relevancia por su capacidad de transmitir mensajes, convirtiéndolos en objetos-documentos. La necesidad de colocarlo dentro
}

destacaba la insularidad social y política de los grupos productores del folklore.

Las conceptualizaciones del folklore no solo destacaban la estabilidad de la cultura folk sino, también, su arraigo a la tierra -su carácter vernáculo. Cuestiones que se asociaban con la autoctonía y la ancestralidad, que tanto los movimientos localistas, regionalistas, y nacionalistas como los estados nación (de diferente signos políticos) han llevado a desarrollos museográficos para construir identidades colectivas arraigadas territorialmente y reclamar lealtades políticas De acuerdo con estas perspectivas, se seleccionaban determinados hechos folklóricos que se ordenaban geográficamente para construir cartografías identitarias sólidas en clave política.

Estos procesos se sustentaron en la separación de los "expertos" poseedores del conocimiento y el público asumido como receptor de dicho conocimiento, asegurándose de este modo el control sobre un discurso monológico. Las representaciones museográficas materializaron los sentidos identitarios a difundir haciéndolos públicos y tornándolos social y políticamente relevantes. Esta lógica va a entrar en crisis - como señalamos en la introducción- a partir de los procesos de descolonización del conocimiento, la auto-reflexión de los folkloristas sobre la historia de los paradigmas de la disciplina y los replanteos de la institución museo. Ello ha llevado a lo que se ha denominado reinvención o descolonización de los museos folklóricos. Este camino es transitado de manera diversa, aunque en todos la marca de origen de sus colecciones va estar presente. El gobierno de Francia opta por soluciones distintas para un museo folklórico regional y otro nacional. Adopta una perspectiva deconstructivista al plantear el Museo de Arlaten como espacio para la reflexión sobre el papel del museo y su fundador en el proceso de construcción de la identidad provenzal y en el caso del MNTP lo inscribe en un museo más abarcativo: el de las Civilizaciones de la Europa Mediterránea, caracterizado como museo de sociedad para experimentar y comprender el mundo en el que vivimos y que presenta los modos y estilos de vida que se cruzan, se reparten y a veces se oponen entre Europa y el Mediterráneo. Todo ello dentro de una perspectiva comparada e intercultural en línea con la construcción de la identidad ciudadana de la Unión Europea ${ }^{11}$ y su integración comunitaria.

En el caso de Norsk Folksemuseum de Noruega y el Nordiska Museet de Suecia, se plantean como museos de historia cultural, específicamente de la vida cotidiana

de un contexto social implicaba un desafío en el campo museográfico para cumplimentar la tarea de interpretar, comunicar y sensibilizar a distintos públicos"

${ }^{11}$ Actualmente la UE desarrolla distintos programas para favorecer la identificación de los ciudadanos con la panregión. Las personas siguen reconociéndose por sus nacionalidades. Por lo que se percibe como imperativo el fortalecimiento de una identidad comunitaria para la integración de Europa. http://ec.europa.eu/news/culture/100309_ es.htm 
y las condiciones de vida del pasado a la actualidad. Estos han ampliado sus colecciones incluyendo sectores sociales antes no considerados y no solo se realizan actuaciones folklóricas de danza y música sino, también, de festividades. Sin embargo, en ambos las exhibiciones de la cultura folklórica rural siguen jugando un papel preponderante para dar cuenta del pasado.

Por su parte, el museo del Pueblo Español -luego de un intrincado proceso en el que ha tenido un significativo peso la colección de trajes folklóricos-, se convertirá en el Museo Nacional de Etnografía -con sede en Teruel- al que se define como centro de la memoria histórica y vida cotidiana de España y propondrá una reflexión sobre los conceptos de identidad y relatividad cultural ${ }^{12}$.

El Museo Folklórico de Tucumán ha incorporado la cultura tradicional de otros colectivos integrantes de la sociedad tucumana, la temática de los conflictos que han atravesado los sectores populares en el pasado y la expansión del folklore en las industrias culturales.

Las reinvenciones mencionadas articulan, en algunos casos políticas radicales -adoptan perspectivas descontructivistas en relación con procesos identitarios locales- y en otros reformistas, que amplían la visión al conjunto de la sociedad en su diversidad e incluyen la historia cultural cotidiana de la misma, pero no cuestionan el modo en que se han construido éstas. Todas, sin embargo, proponen la construcción de identidades en clave plural y de intercambio cultural. Asimismo, si bien acuerdan en la participación comunitaria ésta aún no se halla sistemáticamente integrada.

El análisis expuesto en este trabajo ha tratado de dar cuenta de la creación de los museos de folklore en relación con la representación e interpretación de identidades en el marco de los cambios de paradigmas operados a lo largo de la Modernidad y sus transformaciones con el cambio de siglo.

Buenos Aires, 17 de agosto del 2011

\section{Bibliografía}

Aronsson, P. 2008. The Image of the Peasant within National Museums in the Nordic countries. Societal Change And Ideological Formation among the Rural Population of the Baltic Area 1880-1939, Huddinge: Södertörns högskola: 187-212.

Bauman, R. 2000. "Actuación mediacional y la "autoría" del discurso. Patrimonio Cultural y Comunicación, Museo de Motivos Argentinos J. Hernández: 31-49. (Traducción: Fernando Fischman)

12 http://www.publico.es/culturas/192436/el-mus Fuente: http:// ec.europa.eu/news/culture/100309_es.htm eo-de-la-vida-cotidianaen-teruel
Bennett, T. 1990. The Political Rationality of the Museum Continuum: The Australian Journal of Media \& Culture 3(1):35-55

Bogaart, N. 1983. Hacia nuevos criterios. Museum Museos etnográficos: principios y problema 139: XXXV(3): 145

Burke, P. 1977. Popular Culture in Norway and Sweden1 History Workshop J:1:. 143-150.

Carretero Pérez, A. 2007. Museo del Traje: breve presentación. http://museodeltraje.mcu.es/popups/ publicaciones-electronicas/2007-indumenta0/ Indumenta00-01-ACP.pdf (Ultima consulta 12-7-2011)

Carretero Pérez, A. 1996. Antropólogos y museos etnográficos. Complutum Extra, 6 (11): 329-336

Cefai, D. 2003. L'enquete de terrain. Paris, La Decouverte Colección Recherches

Clifford, J. (1988. Dilemas de la Cultura Barcelona, Gedisa editorial.

Gómez Pedro, A. 2001. Imaginarios sociales y análisis semiótico. Una aproximación a la construcción narrativa de la realidad. Cuadernos FHYCS-UNJU 17: 195-209

Fiskesjö, M. 2007. The Trouble with World Culture Anthropology Today 23 (5):6-11

Götz, N. 2008. Nordic Identities and Asymmetries Nordplus-Infoseminar, Tartu, 8 February.

Hall, S. 1993. "La hegemonía audiovisual" Silvia Delfino comp. La mirada oblicua. Estudios culturales y democracia. Buenos Aires, La marea pp..86-92.

Langdon, E.J 2007. Performance e sua Diversidade como Paradigma Analítico: A Contribuicao da Abordagem de Bauman e Briggs Antropologia em Primeira Mao pp.5-26

Ministerio de Instrucción Pública y Bellas Artes 1935. "Circular general y cuestionario para la recogida de objetos". Anales del Museo del Pueblo Español, 1:33-47.

Ministerio de Instrucción Pública y Bellas Artes 1935. Decreto Fundacional Anales del Museo del Pueblo Español 1: 5-10 (edición facsímil en 1988) http:// museodeltraje.mcu.es/popups/publicaciones/decreto.htm 2007 (Ultima consultada 12 de julio 2011)

Hernández Hernández, F. 1992. Evolución del concepto de museo Revista General de Información y Documentación, 2: (1): 85-97 http://revistas.ucm.es/byd/11321873/ articulos/RGID9292120085A.PDF (Ultima consulta 127-2011) 
Hillstrom, M. 2010. Contested boundaries: Nation, People and Cultural History Museums in Sweden and Norway 1862-1909 Culture Unbound 2 : 583-607

Karp, I. S. D. Lavine, Eds 1991. Exhibiting Cultures: The Poetics and Politics of Museum Display. Smithsonian Institution Press

Konaré Alpha, O. 1983. Hacia un nuevo tipo de museo "etnográfico" en Africa Museum Museos etnográficos: principios y problema 139, XXXV(3): 246-150

Martínez Zuccardi, S. 2010. La literatura del Noroeste argentino. El grupo "La Carpa" y la conciencia poética en la región Anclajes Posiciones y polémicas en la literatura del Noroeste argentino XIV: 14 pp. 145-163

Maure, M. 1993. Nation, paysan et musée. La naissance des musées d'ethnographie dans les pays scandinaves (1870-1904. Terrain $20: 147-157$

Mellado García, A. 2008. Las escritoras del renacimiento literario Occitano del siglo XIX Revista electrónica de Estudios Filológicos 15 http://www.tonosdigital.com/ojs/ index.php/tonos/article/view/206/166 (Ultima consulta 12-7-2011)

Millán de Palavecino, D. 1957. Memoria Anual del Museo Folklórico del Noroeste Manuel Belgrano y del Instituto de Investigaciones Folklóricas, San Miguel de Tucumán, Ministerio de Gobierno de Justicia e Instrucción Pública.

Mignolo, W. 2009. La colonialidad: la cara oculta de la modernidad. http://www.macba.es/PDFs/walter_ mignolo_modernologies_cas.pdf

Ortiz García, C. 1984. La Obra Antropológica de Don Luis De Hoyos Sainz. Actas de las 2as Jornadas de Etnología de Castilla La Mancha, 1984: 17-32 digital.csic.es/ bitstream/10261/13161/1/20090522085857614.pdf (Ultima consulta 12-7-2011)

Palavecino, E. 1959. Áreas de cultura folklórica en el territorio argentino Folklore Argentino. Buenos Aires, Nova: $347-370$

Roigé I Ventura, X., E. Fernández De Paz, I. Arrieta Uurtizberea 2007. El futuro de los museos etnológicos. Consideraciones introductorias para un debate Universidad del País Vasco/Euskal Herriko Unibertsitatea

Roigé i Ventura, X. 2007. “La reinvención del museo etnológico" I. Arrieta Urtizberea ed. Patrimonios culturales y museos: más allá de la historia y del arte, Leioa, UPV Servicio editorial: 19-44.

Segalen, M. 2005. Vie d'un musée, 1937-2005 Paris, Stock, $341 \mathrm{p}$.

Stocking, G. W. 1985. Objects and Others. Essays on Museums and Material Culture History of Anthropology 3 University of Wisconsin Press

Van Ginkel, R. y B. Henkes. 2003. On Peasants and primitive Peoples': Moments of Rapprochement and Distance between Folklore Studies and Anthropology in the Netherlands Ethnos 68 (1):112-134 